\title{
KARAKTERISTIK DOSIMETRI FILM GAFCHROMIC EBT3 PADA BERKAS ELEKTRON DAN FOTON
}

\author{
Syarifatul Ulya ${ }^{1, a)}$, Wahyu Edy Wibowo ${ }^{2, b)}$, Nuruddin ${ }^{2, c)}$, Supriyanto Ardjo \\ Pawiro $^{1, \mathrm{~d})}$
}

1Departemen Fisika, FMIPA, Universitas Indonesia, Depok, 16424

2Departemen Radioterapi, RSCM, Jakarta Pusat, 10430

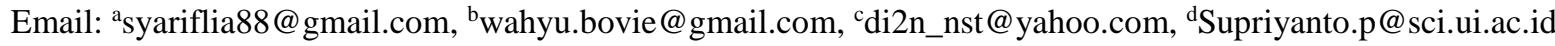

\begin{abstract}
Abstrak
Elektron energi tinggi bermanfaat dalam radioterapi target permukaan dapat pula digunakan sebagai eskalasi dosis sumber berkas foton. Dalam jaminan kualitas radioterapi membutuhkan dosimeteryang akurat, respon yang baik terhadapdosis dan energi, resolusi spasial tinggi serta ekuivalen dengan jaringan. Berdasarkan rekomendasi AAPM TG 55, film merupakan dosimeter utama dalam pengukuran sumber radioterapi. Saat ini, film dosimetri yang sering digunakan dalam keperluan pengukuran salah satunya yaitu film gafchromic EBT3, namun penelitian mengenai karakteristik dan respon dosis pada film gafchromic EBT3 masih terbatas. Sehingga penelitian ini bertujuan untuk mengetahui karakteristik dosimetri film EBT3 pada berkas elektron dan foton. Film EBT3 diradiasi pada lapangan $10 \times 10 \mathrm{~cm}^{2}$ menggunakan berkas foton, elektron dan Cobalt-60 dengan rentang dosis (0-500 cGy). Scanner Epson V700 digunakan untuk pemindaian film dalam evaluasi pixel value. NetOD digunakan sebagai parameter untuk menganalisis karakteristik film EBT3. Nilai uncertainty pengaruh energi berada dalam rentang $\pm 1.95 \%$ yang menunjukkan bahwa film EBT3 memiliki kebergantungan energi realtif kecil. Pemilihan channelscanner menunjukkan bahwa sensitifitas scannerpaling tinggi adalahRed channel.Pixel value dipengaruhi oleh rotasi film namun tidak oleh orientasi flipped. Pada penelitian ini, rotasi optimum dalam pemindaian film adalah posisi landscape.
\end{abstract}

Kata kunci : dosimetri, film, netOD, uncertainty

\begin{abstract}
High energy electron used to treatment radiotherapy superficial target and dose booster photon beam. Quality assurance in radiotherapy required dosimeter which high spatial resolution, good response of doseand energy, and tissue equivalent. Based on the recommendation of AAPM TG 55, the film is primarily dosimeter measurement radiotherapy sources. Recently, film dosimetry usually used in the measurement which one is EBT3 film, however, research about the characteristic and dose response of EBT3 filmare limited. In this study, film EBT3 response on doses and energies variation using electron and photon beams is investigated. Gafchromic EBT3 film was irradiated using electron and photon also cobalt-60 beam energies. In each energy was given $0-500 \mathrm{cGy}$ doses. Film scanning post-irradiation over a period of 72 hours using EPSON V700 and ImageJ were used to film evaluate. NetOD as the parameter to the analysis of EBT3 film characteristics. Uncertainty was required in the range of $\pm 1.95 \%$. Dose responses of the EBT3 film have small energy dependence..Flipped orientation not dependence on the pixel value but rotation orientation dependence for pixel value in EBT3. From this research, we recommended landscape orientation in EBT3 film scanning.
\end{abstract}

Keywords: dosimetry, film, netOD, uncertainty 


\section{PENDAHULUAN}

Radioterapi pada target dangkal atau permukaan sudah lebih dari 50 tahun memanfaatkan penggunaan berkas elektron energi tinggi [1],[2]. Aplikasi dari berkas elektron diantaranya yaitu total skin electron therapy (TSET) dan rotational total skin electron irradiation (RTSEI) [3]. Baru-baru ini telah berkembang pemanfaatan berkas elektron dalam bidang radioterapi yaitu teknik dynamic electron beam radiotherapy. Selain itu, berkas elektron juga digunakan sebagai eskalasi dosis pada teknik 2D radiotherapy (2D-RT), 3D conformal radiotherapy (3D-CRT), intensity-modulated radiotherapy (IMRT) dan volumetricmodulated arc radiotherapy (VMAT) untuk mendapatkan dosis tinggi pada target serta meminimalkan dosis pada organ at risk (OAR) [4].

Keakuratan dosimetri dalam verifikasi berkas elektron dan foton merupakan salah satu aspek yang perlu dikembangkan terkait dengan keberhasilan metode radioterapi [5]. Dosimeter yang biasa digunakan dalam pengukuran dosis berkas elektron menurut rekomendasi American Association of Physicists in Medicine (AAPM) TG 25 adalah bilik ionisasi, thermoluminescent dosimeters (TLD), dioda dan film radiochromic[6]. Bilik ionisasi, TLD dan dioda akurat dalam mengukur dosis titik dalam sumber berkas elektron dan foton. Namun, pengukuran distribusi dosis dua dimensi (2D) menggunakan ketiga dosimeter tersebut kurang efisien karena memerlukan waktu yang lama dalam perhitungan dosis. Dalam mencukupi kebutuhan pengukuran distribusi dosis $2 \mathrm{D}$, film radiochromic telah sukses diaplikasikan dalam radioterapi eksternal maupun internal untuk sumber berkas foton, elektron, dan proton [7]. Salah satu tipenya yaitu film gafchromic, film ini mempunyai komposisi nomor atom efektif yang setara dengan jaringan, resolusi spasial tinggi, dan hasil pengukuran dapat tersimpan secara permanen [8].

Film gafchromic EBT, dirilis tahun 2004 oleh International Specialty Product (ISP), telah menjadi tipe pertama pada film radiochromic menggantikan untuk penggunaan dengan dosis rendah dalam radioterapi. Pada 2009, film gafchromic EBT digantikan oleh film gafchromic EBT2 yang menggabungkan yellow marker dye dalam lapisan aktif dan polimer sisntetis sebagai komponen bahan pengikat. Pada 2012 film EBT3 diperkenalkan untuk mengganti film EBT2 [6]. Perbaikan dilakukan pada film EBT3 sehingga film ini lebih akurat dalam verifikasi dosis.

Buston et al, telah menunjukkan respon film gafchromic EBT ketika di ekspose dengan foton namun pada penelitiannya tidak diteliti respon terhadap masing-masing energi. Hasil penelitiannya diindikasi energi bergantung pada respon dosis pada film gafchromic EBT, setelah range pada berkas dari $50 \mathrm{KVp}$ sampai 10 MVp kurang dari 10\% [7]. Cheung et al, 2006, telah mendemostrasikan bahwa kurva kalibrasi film gafchromic EBT dipengaruhi ukuran lapangan dalam range $5 \times 5 \mathrm{~cm}^{2}$ sampai $40 \times 40 \mathrm{~cm}^{2}[8]$. Namun, pembahasan mengenai respon dosis pada film EBT untuk dosimetri elektron masih terbatas [9].

Oleh karena itu,perlu dilakukan penelitian mengenai respon film gafchromic EBT3 pada energi berkas elektron pada daerah permukaan dalam verifikasi distribusi dosisnya. Hal ini penting karena banyaknya aplikasi energi elektron dalam radioterapi dan membutuhkan quality assurance (QA) untuk verifikasi distribusi dosis terutama pada target dangkal atau permukaan. Penelitian ini bertujuan untuk mengetahui respon film gafchromic EBT3 terhadap berbagai energi berkas elektron dan foton.

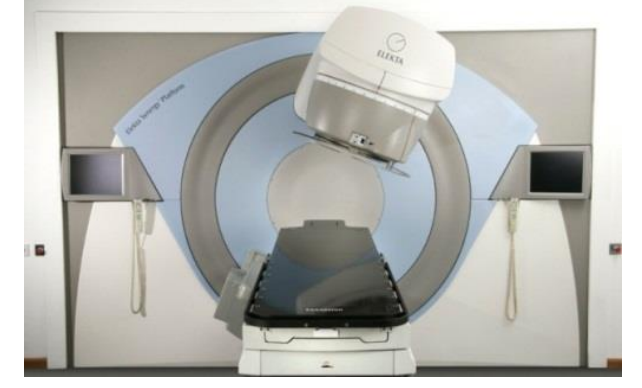

Gambar 1. Pesawat Linac Elekta Synergy® Platform

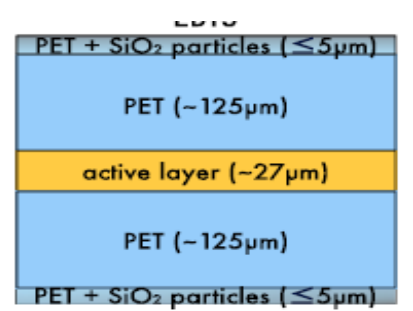

Gambar 2. Struktur film gafchromic EBT3 


\section{METODE PENELITIAN}

Alat bahan yang digunakan dalam penelitian ini diantaranya yaitu: pesawat Linac Elekta Synergy Platform, Linac Elekta Synergy, Cobalt-60 merk SHINVA tipe FCC-8000F, slab solid water RW3, bilik ionisasi, film gafchromic EBT3 lot\#04011501 tanggal kadaluarsa April 2017, scanner Epson Perfection V700, peragkat lunak Film QAPro, ImageJ dan MATLAB.

Film EBT3 memiliki lapirasn yang simetris yaitu ketebalan polyester yang sama $175 \mu \mathrm{m}$. selain itu terdapat partikel silica pada permukaan film untuk mereduksi Newton's Ring [10]. Berikut merupakan rangkaian metode yang dilakukan oleh penulis.

\section{Irradiasi EBT3}

Pengukuran keluaran elektron pada Linac Elekta platform menggunakan aplikator $10 \times 10 \mathrm{~cm}$, frame $10 \times 10 \mathrm{~cm}^{2}$ dan SSD $100 \mathrm{~cm}$ dan lapangan $10 \times 10 \mathrm{~cm}^{2}$. Tabel 1 merupakan kedalaman maksimum dmax berkas elektron. Film gafchromic EBT3 berukuran $35 \times 43 \mathrm{~cm}^{2}$, kemudian dipotong dengan ukuran $2.54 \times 3.17 \mathrm{~cm}^{2}$.

Penyinaran film gafchromic dengan variasi energi mengunakan foton dan elektron, untuk foton energinya $6 \mathrm{MV}, 10 \mathrm{MV}$ dan untuk elektron energinya $6 \mathrm{MeV}, 8 \mathrm{MeV}, 10 \mathrm{MeV}, 12 \mathrm{MeV}, 15 \mathrm{MeV}$ dan 18 $\mathrm{MeV}$ serta Cobalt-60. Pada setiap energy divariasikan menggunakan jangkauan dosis (0-500) cGy. Kedalaman maksimalmenggunakan elektron dengan energi yang kedalaman filmnya seperti pada Tabel 2. Sedangan berkas foton energi $6 \mathrm{MV}, 10 \mathrm{MV}$ dan cobalt-60 kedalaman maksimum masing-masingnya adalah $1.5 \mathrm{~cm}, 2.5 \mathrm{~cm}$, dan $0.5 \mathrm{~cm}$. Pembacaan film dengan menggunakan softwareImageJ, khusus untuk energi $6 \mathrm{MeV}$ bacaan pixel value dibandingkan dengan MATLAB dan film QAPro.

\section{Digitalisasi Film EBT3}

Melakukan pemindaian film setelah 72 jam yang merujuk pada penelitian Borca, 2013 menggunakan Epson Perfection V700 dengan memvariasikan ukuran region of interest ROI [8].Format yang digunakan yaitu resolusi $72 \mathrm{dpi}, 48$ bit, dan disimpan dalam format TIFF [5].

\section{Analisis Respon Film EBT3}

Analisis dilakukan untuk mengetahui hubungan antara netOD dan dosis pada masing-masing energi dalam mendapatkan kurva respon EBT3. NetOD digunakan sebagai parameter untuk menganalisis karakteristik film EBT3, mengikuti persamaan (1).

$$
\text { net } O D=\log _{10}\left(\frac{P V_{u m}}{P V_{k x}}\right)
$$

dengan $P V_{u n}$ merupakan pixel value film tanpa disinar, dan $P V_{E x}$ merupakan pixel value film setelah disinar dengan energi foton maupun elektron [5].

Tabel 1. Kedalaman maksimum pada energi elektron

\begin{tabular}{cr}
\hline Energi $(\mathbf{M e V})$ & $\boldsymbol{d}_{\max }(\mathbf{c m})$ \\
\hline 6 & 1,47 \\
8 & 1.47 \\
10 & 2.48 \\
12 & 2,48 \\
15 & 2,47 \\
18 & 1,98 \\
\hline
\end{tabular}




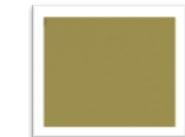

(a) 0 cGy

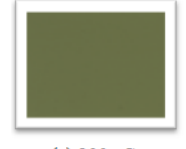

(e) $200 \mathrm{cGy}$

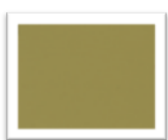

(b) $10 \mathrm{cGy}$

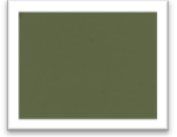

(f) $300 \mathrm{cGy}$

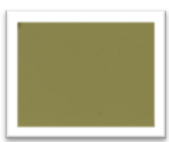

(c) $50 \mathrm{cGy}$

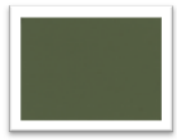

(g) $400 \mathrm{cGy}$

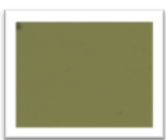

(d) 100 cGy

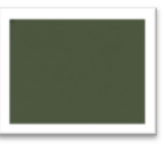

(h) $500 \mathrm{~Gy}$
Gambar 3. Film digital dari sampel diiradiasi dengan dosis yang berbeda

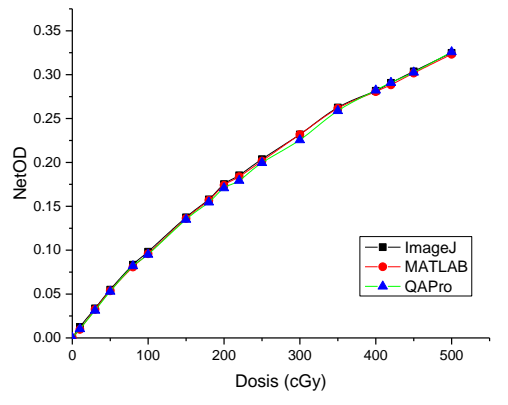

Gambar 4. Perbandingan nilai netOD pada software yang berbeda

\section{HASIL DAN PEMBAHASAN}

\section{Pengukuran Optical density pada masing-masing Software}

Penelitian ini melakukan irradiasi film EBT3 menggunakan berkas energi foton 6 dan 10 MV serta berkas elektron 6, 8, 10, 12, 15 dan $18 \mathrm{MeV}$ pada linac Synergy Platform di rumah sakit Cipto Mangunkusumo, Jakarta. Selain itu, film diradiasi menggunakan Cobalt-60 merk SHINVA tipe FCC8000F. Setelah diradiasi, film EBT3 dipindai untuk mendapatkan film digital menggunakan scanner Epson perfection V700. Kemudian dilakukan pembacaan nilai pixel film EBT3 film digital menggunakansoftware yang berbeda yaitu ImageJ, Matlab dan Film QAPro serta membandingkannya untuk mengetahui software yang optimal dalam pembacaan film digital. Penentukan software yang paling optimal dalam menghitung pixel value film digital untuk mendapatkan respon film dapat dilihat pada Gambar 4.

Gambar 4 mendiskripsikan hubungan dosis dengan netOD pada variasi software pada energi elektron 6 $\mathrm{MeV}$, dapat diketahui bahwa antara ImageJ, Matlab dan QA Pro memiliki respon yang sama hanya saja pada dosis antara 200-350 cGy software QA Pro lebih rendah dalam perhitungan netOD. Berdasarkan hasil analisis Gambar 4, ImageJdigunakan dalam analisis data respon film gafchromicEBT3 terhadap masing-masing energi.

\section{Perbandingan netOD pada energi}

Pada variasi dosis dapat diketahui bahwa semakin tinggi dosis yang diberikan maka nilai netODfilm EBT3 yang didapatkan semakin besar pula. Hal ini dikarenakan adanya polimerisasi film yang menyebabkan perubahan warna menjadi semakin hitam dengan bertambahnya dosis. Hal ini sesuai dengan penelitian yang dilakukan oleh Sorriaux (2016) [11].

Dalam penentuan respon film EBT3 pada setiap energi foton maupun elektron dianalisis dengan menggunakan Persamaan (2), hasilnya dapat dilihat pada Gambar 6. Berdasarkan hasil analisis nilai uncertainty pada masing-masing energi elektron rata-rata mengalami penurunan dengan kenaikan energi elektron yang diberikan..

$$
\sigma_{\text {netoD }}=\frac{1}{\ln 10} \sqrt{\frac{\sigma_{\text {unx }}}{P V_{\text {Wnx }}}+\frac{\sigma_{\text {gxD }}}{P V_{\text {gxD }}}}
$$

Analisis penentuan ketidakpastian (uncertainty) pembacaan film EBT3 pada energi foton, elektron dan cobalt-60 dapat dianalisis menggunakan Persamaan (2). Dalam penelitian ini nilai uncertainty rata-rata pada pengukuran ini adalah $\pm 1.95 \%$ (Gambar 6). Hasil ini lebih rendah jika dibandingkan dengan dengan penelitian yang dilakukan oleh Fan-Chi Su pada tahun 2007( $\pm 4 \%)[2]$. 


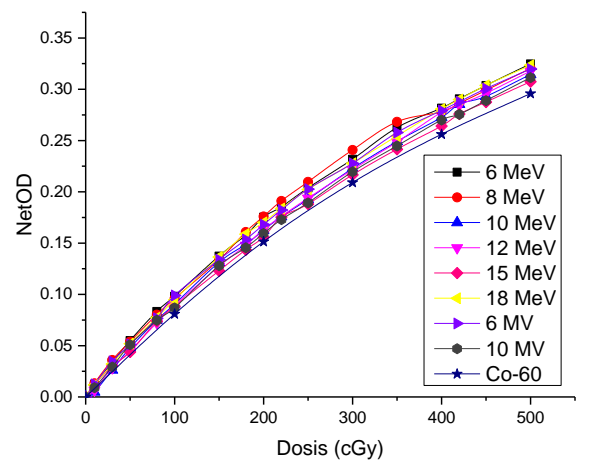

Gambar 5. Hubungan antara dosis dengan net $O D$ pada seluruh energi

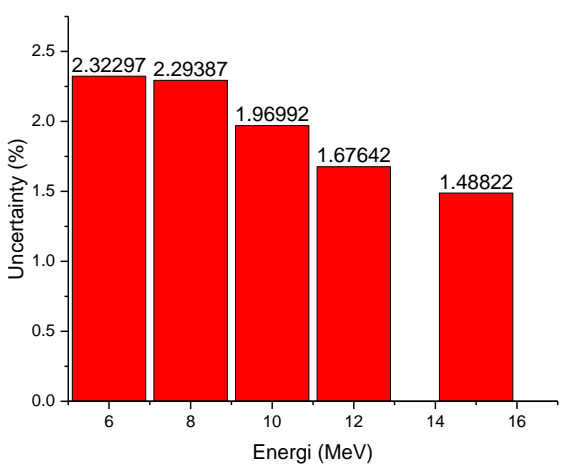

Gambar 6.Uncertainty pengukuran pada masing-masing energi elektron

Penelitian serupa dilakukan oleh Sorriaux et al. (2013) yang mempelajari karakteristik pada dosimetri EBT3 dalam berkas foton dan elektron. Berkas elektron tunggal $6 \mathrm{MeV}$, total uncertainty diterima antara $2 \%$ untuk kurva kalibrasi pada level dosis diatas 0,8 Gy [9]. Sedangkan penelitian Moylan et al. memasukkan berkas elektron $9 \mathrm{MeV}$ dalam penelitiannya, dimana film EBT3 diuji dosimetri in vivo, konsentrasi pada pengaruh ukuran film, ukuran ROI, dan lokasi scanning film. Akurasi kombinasi dosimetri dengan berkas foton $6 \mathrm{MV}$ telah dilaporkan 2,6\% [12]. Jika dibandingkan dengan penelitian sebelumnya, penelitian ini lebih banyak variasi dosis serta energinya, sehingga melalui penelitian ini respon energy film EBT3 terhadap berkas energi foton dan elektron dapat diketahui bahwa film EBT3 terpengaruh oleh dosis namun pengaruh terhadap energi yang berbeda relatif kecil.

\section{Dosis Serap pada Setiap Channel}

Selain analisis respon EBT3 terhadap energi,pengaruh terhadap masing-masing channel RGB pada scannerjuga dilakukan. Perbandingan nilai netOD pada Red, Green dan Bluechannelmenggunakan softwareImageJ pada energi $6 \mathrm{MeV}$ dan $6 \mathrm{MV}$ pada Gambar 7.

Tabel 2. Perbandingan nilai Uncertainty

\begin{tabular}{lll}
\hline Parameter & $\begin{array}{l}\text { Uncertainty } \\
(\mathbf{\%})\end{array}$ & Referensi \\
\hline $\begin{array}{l}\text { Berkas elektron } \\
\text { (EBT) }\end{array}$ & 4 & $\begin{array}{l}\text { Fan-Chi Su } \\
\text { et al, 2007 }\end{array}$ \\
6 MV (EBT3) & 4 & $\begin{array}{l}\text { Borca et al, } \\
2013 \\
\text { Sorriaux et } \\
\text { al, 2013 }\end{array}$ \\
$\begin{array}{l}\text { Berkas elektron } \\
\text { (EBT3) }\end{array}$ & 2 & $\begin{array}{l}\text { Moylan et } \\
\text { al, 2013 }\end{array}$ \\
$\begin{array}{l}\text { Berkas foton 6 MV } \\
\text { dan elektron 9 MeV }\end{array}$ & 2.6 & $\begin{array}{l}\text { Ulya et al, } \\
\text { (EBT2) }\end{array}$ \\
$\begin{array}{l}\text { Elektron dan foton } \\
\text { (EBT3) }\end{array}$ & 1.95 & \\
\hline
\end{tabular}




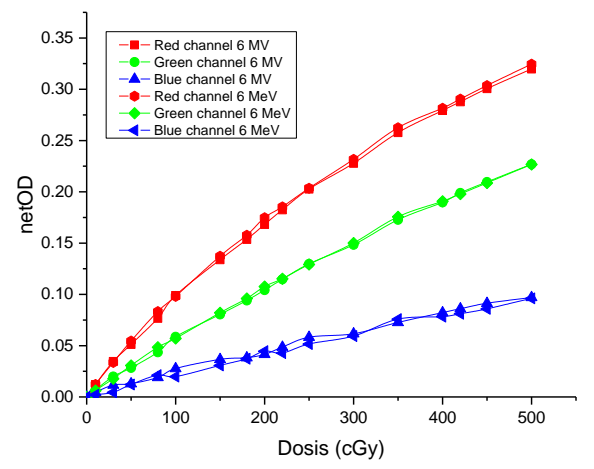

Gambar 7. Grafik Hubungan antara netOD EBT3 terhadap dosis dengan setiap channel pada energi $6 \mathrm{MeV}$.

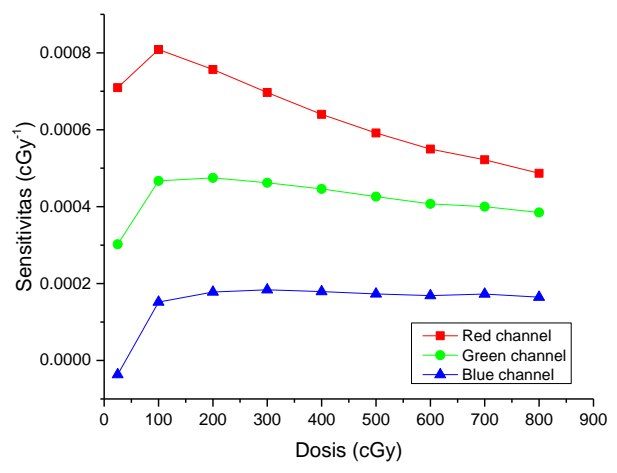

Gambar 8. Sensitivitas pada Cobalt-60

Gambar 8 menunjukkan redchannel memiliki netOD yang paling besar yang berarti responnya paling tinggi. Hasil tersebut serupa dengan penelitian Farah (2014) dan Papaconstadopoulos (2014)[13], [14]. Hal ini karena puncak spektra film EBT3 berada dalam rentang 630-700 nm, sehingga hasil pemindaian paling optimal didapatkan dengan Red channel, sedangkan Blue channelmemiliki nilai yang paling rendah. Hal ini mengindifikasi bahwaBlue channelterjadi efek pertubansi yang meningkatkan noise pada film digital sehingga tidak cocok sebagai parameter dalam menentukan pengaruh respon dosis, hasil ini sesuai dengan penelitian Sipilä (2016)[5], [15].

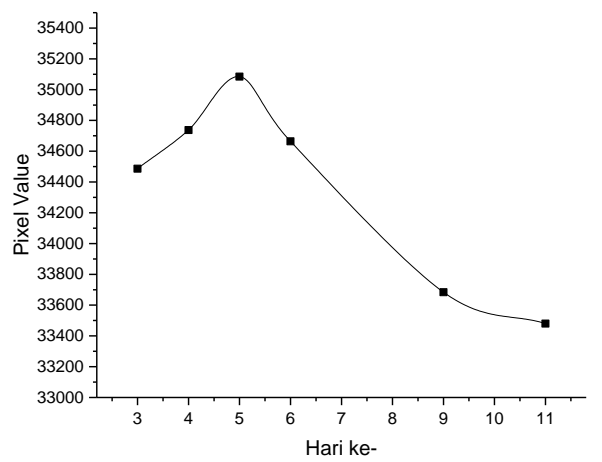

Gambar 9.Variasi waktu pemindaian setelah iradiasi

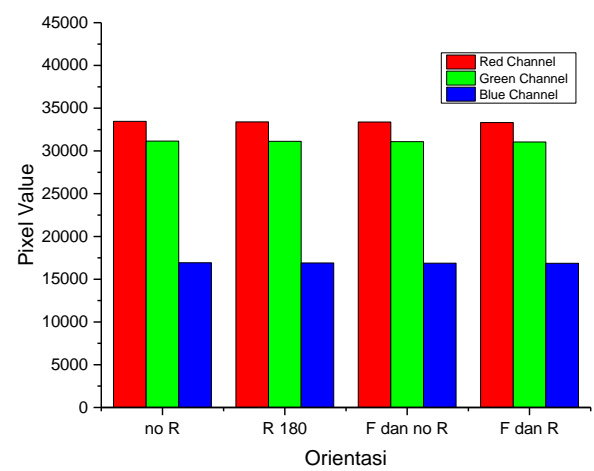

Gambar 10. Pengaruh orientasi pembalikan film(flipped)

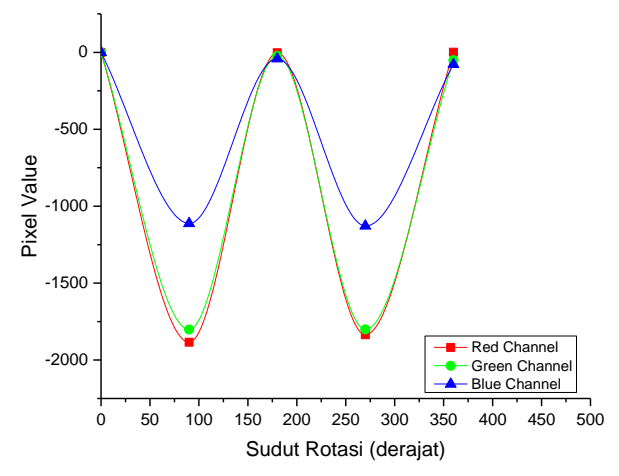

Gambar 11. Pengaruh Rotasi pada film EBT3 


\section{Pengaruh waktu pemindaian, orientasi dan rotasi pada film EBT3}

Dalam upaya mengatahui karakteristik film EBT3, dilakukan beberapa perlakuaan ketika pemindaian dengan menggunakan scanner Epson V700. Variasi waktu posiradiation pada film EBT3 dengan dosis 200cGy dapat dilihat pada Gambar 9. Nilai piksel meningkat ketika hari ke 5 setelah itu mengalami penurunan sampai hari ke 11. Pada penelitian yang dilakukan oleh Sipilä (2016), nilai piksel paling tinggi yaitu pada hari ke 4. Perbedaan ini dimungkinkan karena pemindaian yang berulang pada film EBT3 dan juga penggunaan scanner yang berbeda pula [5]. Oleh karena itu, disarankan untuk penelitian kedepan, variasi watu pemindaian dilakukan pada film masing-masing variasi waktu, bukan menggunakan satu film dipindai secara berulang.

Orientasi pada film EBT3 ketika pemindaian tidak mempengaruhi pixel value film baik pada posisi dibalik (flipped) maupun tidak (Gambar 10). Hal ini karena film EBT3 memiliki komposisi lapisan yang simetris. Orientasi film pada flippeddan dirotasikan $180^{\circ}$ tidak mempengaruhi nilai piksel, baik pada red, green, blue channel. Berbeda halnya dengan pengaruh rotasi film ketika pemindaian atau orientasi landscape dan portrait film EBT3 mempengaruhi nilai piksel(Gambar 11). Ketika rotasinya $90^{\circ}$ dan $180^{\circ}$ (rotasi portrait) nilai piksel menurun jika dibandingkan dengan rotasi $0^{\circ}$ dan $360^{\circ}$. Berdasarkan hasil ini maka film EBT3 harus diberikan tanda (mark) agar arah orientasinya tetap sama baik ketika iradiasi maupun saat pemindaan. Selain itu, orientasi landscape dianjurkan dalam pemindaian film EBT3 karena memiliki respon yang lebih tinggi jika dibandingkan orientasi portrait [8].

\section{KESIMPULAN}

Berdasarkan hasil dan pembahasan pada penelitian ini, dapat disimpulkan bahwa nilai variasi energi pada elektron, foton dan Cobalt-60 yaitu $\pm 1.95 \%$ sehingga film pengaruh terhadap masing-masing energinya relatif kecil. Red channel direkomendasikan dalam pemilihan channel untuk analisis. Selain itu, film EBT3 dipengaruhi oleh rorasi film namun tidak dipengaruhi oleh pembalikan film (flipped) ketika pemindaian.

\section{UCAPAN TERIMA KASIH}

Terima kasih kepada Fisikawan Medis di Instalasi Radioterapi RSUPN Dr. Cipto Mangunkusumo dan RS Persahabatan, Jakarta serta seluruh civitas akademik peminatan fisika medis dan biofisika Universitas Indonesia yang telah mendukung proses penelitian ini.

\section{DAFTAR ACUAN}

[1] K. R. Hogstrom and P. R. Almond, "Review of electron beam therapy physics," Phys. Med. Biol., vol. 51, pp. 455-489, 2006.

[2] F. Su, Y. Liu, S. Stathakis, C. Shi, and C. Esquivel, "Dosimetry characteristics of gafchromic EBT film responding to therapeutic electron beams," Appl. Radiat. Isot., vol. 65, pp. 1187-1192, 2007.

[3] J. El, N. Fournier-bidoz, A. Mazal, G. Fares, and J. Rosenwald, "Practical use of Gafchromic Ò EBT films in electron beams for in-phantom dose distribution measurements and monitor units verification," Phys. Medica, vol. 27, no. 2, pp. 81-88, 2011.

[4] M. I. K. M. K. Am, R. I. M. C. C. Hau, J. O. S. Uen, P. E. H. K. C. Hoi, and P. E. M. L. T. Eo, "Intensity-Modulated Radiotherapy in Nasopharyngeal Carcinoma: Dosimetric Advantage Over Conventional Plans and Feasibility of Dose Escalation," Int. J. Radiat. Oncol. Biol. Phys., vol. 56, no. 1, pp. 145-157, 2003.

[5] P. Sipilä, J. Ojala, S. Kaijaluoto, and I. Jokelainen, "Gafchromic EBT3 film dosimetry in electron beams - energy dependence and improved film read-out," J. Appl. Clin. Med. Phys., vol. 17, no. 1, pp. 360-373, 2016. 
[6] B. J. Gerbi, J. a Antolak, F. C. Deibel, D. S. Followill, M. G. Herman, P. D. Higgins, M. S. Huq, D. N. Mihailidis, E. D. Yorke, K. R. Hogstrom, and F. M. Khan, "Recommendations for clinical electron beam dosimetry: supplement to the recommendations of Task Group 25.," Med. Phys., vol. 36, no. 7, pp. 3239-3279, 2009.

[7] N. Donmez Kesen, A. Cakir, M. Okutan, and H. Bilge, "A comparison of TPS and different measurement techniques in small-field electron beams," Med. Dosim., vol. 40, no. 1, pp. 9-15, 2015.

[8] V. C. Borca, M. Pasquino, G. Russo, P. Grosso, D. Cante, P. Sciacero, G. Girelli, M. Rosa, L. Porta, and S. Tofani, "Dosimetric characterization and use of GAFCHROMIC EBT3 film for IMRT dose verification," jounal Appl. Clin. Med. Phys., vol. 14, no. 2, pp. 158-171, 2013.

[9] J. Sorriaux, A. Kacperek, S. Rossomme, J. A. Lee, D. Bertrand, S. Vynckier, and E. Sterpin, "Evaluation of Gafchromic Ò EBT3 films characteristics in therapy photon, electron and proton beams," Phys. Medica, pp. 1-10, 2012.

[10]D. Lewis, A. Micke, and X. Yu, "An efficient protocol for radiochromic film dosimetry combining calibration and measurement in a single scan," Med. Phys., vol. 39, no. 10, pp. 63396350, 2012.

[11]J. Sorriaux, A. Kacperek, S. Rossomme, J. A. Lee, D. Bertrand, S. Vynckier, and E. Sterpin, "Physica Medica Evaluation of Gafchromic Oे EBT3 fi lms characteristics in therapy photon, electron and proton beams," Phys. Medica, pp. 1-8, 2013.

[12]R. Moylan, T. Aland, and T. Kairn, "Dosimetric accuracy of Gafchromic EBT2 and EBT3 film for in vivo dosimetry," Australas Physic Eng Sci Med, 2013.

[13]N. Farah, Z. Francis, and M. Abboud, "Analysis of the EBT3 Gafchromic fi lm irradiated with 6 MV photons and $6 \mathrm{MeV}$ electrons using re fl ective mode scanners," Phys. Medica, vol. 30, pp. 708-712, 2014.

[14]P. Papaconstadopoulos, G. Hegyi, J. Seuntjens, S. Devic, P. Papaconstadopoulos, G. Hegyi, and J. Seuntjens, "A protocol for EBT3 radiochromic film dosimetry using reflection scanning A protocol for EBT3 radiochromic film dosimetry using reflection scanning," Med. Phys., vol. 41, no. 12 , pp. 122101-1 - 122101-6, 2014.

[15]W. Crijns, F. Maes, U. A. Van Der Heide, and F. Van Den Heuvel, "Calibrating page sized Gafchromic EBT3 films,” Int. J. Med. Phys. Res. Pract., vol. 012102, 2013. 